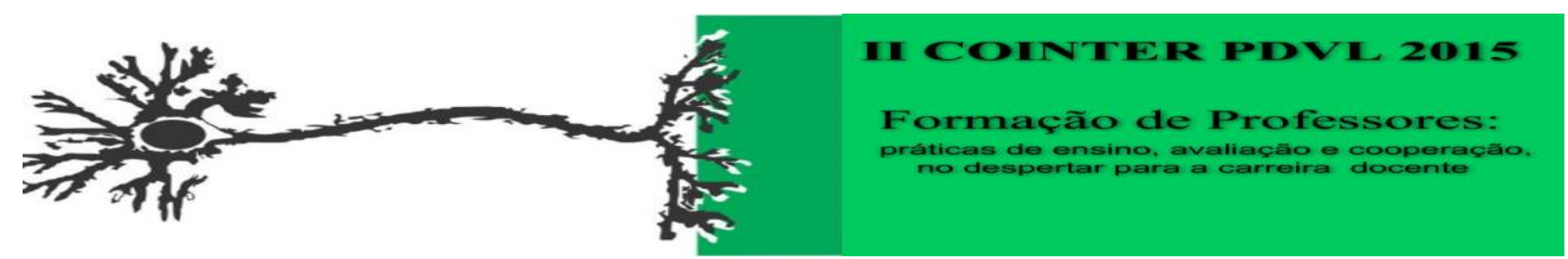

\title{
PRODUÇÃO DE DESENHO ANIMADO APLICADOS A PROBLEMAS MATEMÁTICOS, NO ÂMBITO DAS ESCOLAS ASSISTIDAS PELO PIBID - URUÇUÍ-PI
}

\author{
Apresentação: Pôster
}

\begin{abstract}
Erivan Silva Costa ${ }^{1}$; Danielson Almeida Sousa Tomaz ${ }^{2}$; Paulo Nilton dos Santos Santiago ${ }^{3}$; William Borges de Araújo ${ }^{4}$; Robson de Abreu Fonseca ${ }^{5}$
\end{abstract}

\section{Introdução}

O presente trabalho visa descrever situações vivênciadas no âmbito das escolas assitidas pelo PIBID ${ }^{6}$ matemática em Uruçuí-PI. Os momentos de promoção do ensino de matemática por meio de filmes de ilustrações e desenhos trouxeram modificações consideraveis que serão mostradas de forma sucinta, de acordo com a evolução percebida no campo de pesquisa.

A Produção de desenho animado para problemas de matemática, no âmbito das escolas assistidas pelo PIBID - Uruçuí-PI, tema da pesquisa, trouxe inquietações para busca de efeitos desta prática vivenciada nos trabalhos de CASTRO FILHO(2015), disponiveis nos anais do 4 SIPMAT$^{7}$, nas instituições do município. Problemas levantados no trabalho circundam a dúvida de como levar interatividade entre conteúdo e arte para o ensino dentro de sala de aula? Ou ainda; quais as contribuições do relacionamento entre desenho e conteúdo para o ensino e aprendizagem? E não obstante ao intuito do trabalho a questão de como conciliar diferentes aspectos de sabedoria dentro do ambiente de sala de aula com atividades em grupo com ajuda de filmes produzides por meios informatizados?

O interesse pela utilização desta ferramenta de ensino surgiu pelas experiencias de CASTRO FILHO(2015). Para o município, planejou-se primeiro a produção de desenhos pelos alunos, objetivando a criação de filmes com estes próprios desenhos. Mas durante este processo observou-

\footnotetext{
${ }^{1}$ Licenciatura em Matemática, IFPI, erivan.96@hotmail.com

${ }^{2}$ Licenciatura em Matemática, IFPI, danielson.tomaz@hotmail.com.br

${ }^{3}$ Licenciatura em Matemática, IFPI, paulonewtonsantiago@ hotmail.com

${ }^{4}$ Licenciatura em Matemática, IFPI, williamba66@hotmail.com

${ }^{5}$ Prof. Me. De Matemática do IFPI, robson.fonseca@ifpi.edu.br

${ }^{6}$ Programa Institucional de Bolsa de Iniciação à Docência.

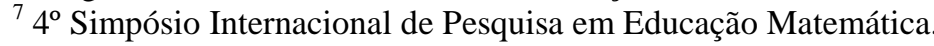


se um notório desenteresse por parte dos mesmos. Diante deste fato, brotou a necessidade de novas ferramentas tecnologicas da informação, para estar auxiliando nesta busca por atenção. Uma vez que “..., a adoção dos recursos da informática na prática de sala de aula pode provocar importantes mudanças no processo de educação nas escolas, ao estimular a revisão das ações dos agentes escolares." (COX, 2003, p. 53). Assim os resultados destas hipóteses seguem no decorrer deste trabalho.

\section{Fundamentação Teórica}

$\mathrm{Na}$ tentativa de solucionar os questionamentos do trabalho, contamos com o apoio das discurções de Castro Filho (2015), Cox (2003), Figueiredo(1996) e Borba(2013), discurssões estas que relatavam esperiências positivas com a utilização de meios informátizados na promoção do ensino de matemática em sala de aula. Assim como discute Castro Filho (2015):

\footnotetext{
No modelo de informática educativa, as vantagens para os processos de ensino e de aprendizagem podem ser vislumbradas a partir do momento em que os sujeitos passam a utilizar os equipamentos visando a aquisição de informações e a construção de conhecimentos. (CASTRO FILHO,2015)
}

Tais conhecimentos foram buscados para compreenção das definições de função, por parte dos alunos. A informática educativa foi assitida quando se introduziu um software de edição de filmes para trabalhar o conteúdo de matemática com os alunos.

O conteúdo de funções trabalhado nos videos teve por fundamentação a definição de Figueiredo (1996):

Definição 1.1 Uma função $f$, de um conjunto A em um conjunto B é uma regra que a cada elemento x $\in$ A associa um elemento $f(\mathrm{x})$ em B. $f(\mathrm{x})$ é chamado o valor de $f$ no elemento $\mathrm{x}$. O conjunto A é chamado o domínio (conhecido também por campo de definição) da função $f$, e o conjunto B é chamado o contradomínio. Usamos a seguinte notação que explicita o domínio e o contradomínio da função: $f: \mathrm{A} \rightarrow \mathrm{B}$. Não é demais repetir que, dada uma função $f: \mathrm{A} \rightarrow \mathrm{B}$, o valor da função é um elemento $\mathrm{x} \in \mathrm{A}$ é univocamente determinado.

A partir desta definição e aproveitando exemplos cotidianos, conseguiu-se trabalhar com os conteúdos de forma objetiva e clara para o alunado, as definições dos matériais didáticos utilizados na escola.

\section{Metodologia}

A metodologia utilizada neste trabalho é o método qualitativo em educação matemática, visto que, segundo Borba (2013) pesquisas realizadas segundo uma abordagem qualitativa nos fornece informações mais descritivas, que primam pelo significado dado às ações. 
O campo de estudo, se evidência por alunos do ensino fundamental maior, da Unidade Escolar Municipal Arica Leal e Unidade Escolar Lourdes Cury, localizadas na cidade de Uruçuí-Pi, âmbas assistidas pelo PIBID-matemática.

Como primeira ação tivemos a identificação dos alunos que gostavam de desenhar, em seguida os alunos que gostavam de contar histórias, para assim chegarmos aos grupos de alunos que tinham mais atenção nas atividades de informátização das tarefas. Utilizou-se software de edição de filmes, e criação de um enredo para discurssão e adaptação dos temas de matemática.

Em um segundo momento, tivemos a criação, exibição e coleta de relatos, sobre as atividades propostas, coletas estas que se deram por meio da aplicação de um questionário no qual os alunos poderam resolver alguns problemas relacionados ao conteúdo abordado e também tiveram a oportunidade de expor sua opinião. Para assim montarmos um perfil dos alunos submetidos à prática de ensino de matemática utilizando filmes com desenhos animados.

\section{Resultados e Discussões}

A produção e edição dos filmes com desenhos animados aplicados aos problemas de função poderam ser editados através de software livre como o MUVIZU, e outros softwares como o Windows Movie Maker. Os videos foram elaborados de acordo com a teoria de Figueiredo (1996) sobre as funções e exibidos em aulas de 100 minutos, onde 50 minutos eram destinados ao filme e os outros 50 minutos destinados a atividades referentes ao filme.

Figura 1: imagem do filme exibido aos alunos.

Figura 2: exibição de filmes.
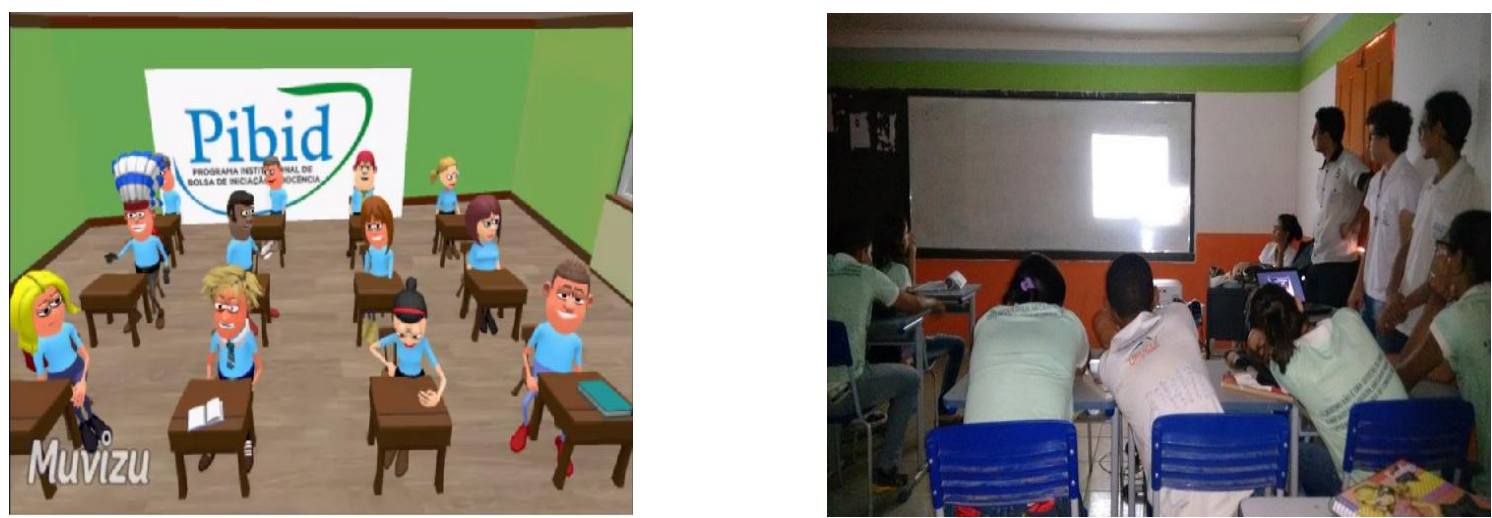

Fonte: Arquivo do autor

Na exibição dos filmes perceberam-se as caracteristicas descritas por Cox (2003), quando os alunos mostraram-se atraidos pelos métodos utilizados, onde segundo os relatos de alguns, é uma maneira bastante atraente de se absorver o conteúdo. Uns dos indicativos positivos sobre esta 
suspeita recaem no relato do aluno A quando questionado: Qual a sua opinião sobre a explicação de função por meio de um filme com desenhos animados?

Figura 3: relato do aluno A ao questionamento.

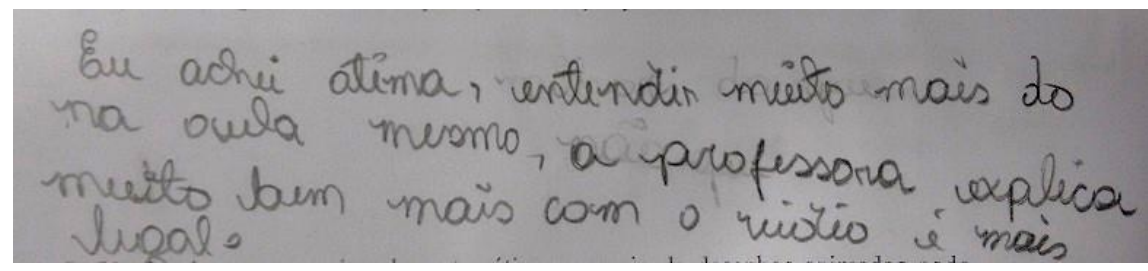

Fonte: do autor

A partir dos relatos dos alunos, percebeu-se que em mais de $90 \%$ dos alunos caracterizou-se um comportamento positivo em relação aos filmes. Em se tratando da resolução de problemas propostos pelos filmes notou-se uma acessibilidade por uma grande parte da turma, o que não era típico antes da exibição dos filmes.

\section{Conclusões}

Durante o processo de pesquisa, percebeu-se caracteristicas positivas na maioria dos alunos. No que se trata do ensino de função conseguiu-se manter a atenção dos alunos na exposição das definições, o que só era conseguido quando a professora resolvia problemas. Além do que houve um engajamento consideravel para resolução dos problemas propostos.

O trabalho de exibição de filmes para ensino de função se mostrou efetivo para aprendizado do aluno, e o trabalho do professor e futuro professor, resolvendo assim os problemas levantados no inicio do trabalho de maneira positiva.

\section{Referências}

BORBA, Marcelo de Carvalho. Pesquisa Qualitativa em Educação Matemática. Belo Horizonte, MG: Autêntica Editora, 2013.

CASTRO FILHO, J.A. Formação de professores que ensinam matemática no contexto da cibercultura. Anais [do] $4^{\circ}$ Simpósio: Educação Matemática E contexto da diversidade cultural, Ilheús, BA: Sociedade Brasileira de Educação Matemática 2015.

COX, Kenia Kodel. Informática na educação escolar. Campinas, SP: Autores Associados, 2013.

FIGUEIREDO, Djairro Guedes de. Análise I. LTC. Rio de Janeiro, RJ, 1996. 